\title{
Towards refining the carbon budget of the Taiwan Orogeny
}

BlattManN, T.M. ${ }^{1 *}$, Lin, B. ${ }^{2}$, LiU, Z. ${ }^{2}$, WANG, S.-L. ${ }^{3}$, MÄRKI, L. ${ }^{4}$, EGLINTON, T.I. ${ }^{4}$, LUPKER, M. ${ }^{4}$

${ }^{1}$ Biogeochemistry Research Center, Japan Agency for

Marine-Earth Science and Technology, Yokosuka, Japan,

*correspondence: blattmannt@jamstec.go.jp

${ }^{2}$ Key State Laboratory of Marine Geology, Tongji University, Shanghai, China

${ }^{3}$ Department of Geosciences, National Taiwan University, Taipei, Taiwan

${ }^{4}$ Geological Insitute, ETH Zurich, Switzerland

The circulation of carbon between different pools on Earth's surface governs the trajectory of atmospheric chemistry over geological timescales. Chemical weathering of silicates by carbonic acid draws down $\mathrm{CO}_{2}$, while sulfuric acid weathering of carbonates and kerogen oxidation release $\mathrm{CO}_{2}$. Contradicting the "Raymo Hypothesis" [1], recent quantitative insights from the Taiwan Orogeny indicate an emission of $\mathrm{CO}_{2}$ due to the superimposed effects of the different chemical weathering pathways driven mainly by sulfuric acid decomposition of carbonates [2].

However, considering terrestrial biospheric organic carbon export and burial in adjacent marine sediments, which represents the product of land-based photosynthesis, these geological $\mathrm{CO}_{2}$ emissions are compensated, turning the Taiwan Orogeny into a net sink of $\mathrm{CO}_{2}$ over geological timescales. The fine balance between organic and inorganic geochemical cycles raise the need to improve our understanding of the fate of terrestrial organic carbon in the world's oceans $[2,3]$.

In order to refine the carbon budget of the Taiwan Orogeny as well as globally, we highlight the need to conduct more radiocarbon geochemical investigations on (a) sedimentary organic carbon which constrains proportions of biospherically-sourced versus kerogenous organic matter and (b) dissolved inorganic carbon which provides quantitative constraint on the contributions from chemical weathering pathways by way of carbonic acid or sulfuric acid weathering of exhumed bedrock. Such investigations should be carried out in time series in order to accurately gauge long-term average geochemical carbon fluxes and detect changes in our dynamically responding Earth system.

[1] Raymo, M. et al. (1988) Geology 16, 649-653.

[2] Blattmann, T.M. et al. (2019) Sci. Rep. 9, 1-8.

[3] Lin, B. et al. (2020) Earth Planet. Sci. Lett. 539, 1-9. 